\title{
Optimization of Dietary Phosphorus Utilization for Eco-friendly Pig Production: An Overview
}

\section{Papori Talukdar ${ }^{1 *}$, Lakhyajyoti Bora ${ }^{1}$, Anil Deka ${ }^{1}$, Simson Soren ${ }^{1}$ and Dibyajyoti Talukdar ${ }^{2}$}

${ }^{1}$ College Veterinary Science, Assam Agricultural University, Assam, India

${ }^{2}$ College of Veterinary Sciences and A.H., Central Agricultural University, Mizoram, India

*Corresponding Author: Papori Talukdar, College Veterinary Science, Assam Agricultural University, Assam, India.
Received: July 26, 2021

Published: November 26, 2021

(C) All rights are reserved by Papori

Talukdar., et al.

\begin{abstract}
Phosphorus (P) is an important major mineral element required by all livestock species. Dietary phosphorus can't be fully utilized by monogastric species especially pigs due to several dietary factors. As a result, most of this mineral is excreted through faeces without utilization and is considered as economic loss as well has also environmental impact due to its excess release in the soil and water. The majority of oilseeds and meals used for ration formulation are phytate bound and unavailable to the animal. To overcome the problem various strategies have been developed and it includes dietetic addition of microbial phytase, giving low phytate diet and grains containing a high level of inherent phytase, oilseed meals, and the making of phytase-secreting transgenic animals etc. 'Enviropig' is a very recent biotechnological tool through genetic engineering technique that could process phytates and able to digest plant phytate phosphorus. It can produce enzyme phytase in their saliva so that the pigs can degrade normally dietary indigestible phytate. In the present manuscript, the authors discussed the potentiality of Enviropig and its scope in near future for eco-friendly pig production.
\end{abstract}

Keywords: Pig; Phosphorus; Utilization

\section{Introduction}

Swine husbandry is a very profitable and fastest-growing enterprise that could meet the increasing demand for meat worldwide [1]. But one of the major problems in swine farming is swine excreta having a very strong odour due to phosphorus and nitrogen released into the environment. It was reported that an amount of $30 \%$ or more phosphorus (P) and nitrogen (N) was released from the livestock into the soil and freshwater which creates a serious issue for the environment [2]. In most of the countries of the world, a huge amount of pig manures are daily voided in the soil and as a result, there was constant accretion of phosphorus in the soil but its utilization and excretion is a subject of great apprehension $[3,4]$. Moreover, these releases of phosphorus and nitrogen are menacing to the farm economy as these valuable nutrients are ex- creted from the body without utilization [5].

Usually, in aquatic ecosystems, nitrogen and phosphorus naturally arise, which prop up the growth of algae and aquatic plants [5]. It was observed that when the quantities of these nutrients are more they can go into the surroundings particularly ponds, rivers and sea which can enhance the expansion of green and blue algae. This type of algal blooms used up the oxygen from the water and ultimately causes asphyxia in aquatic creatures and also contaminated the water by producing toxins and which may help for bacterial growth and it can be harmful to humans as well animals [6].

\section{Phosphorus utilization in pigs}

In swine ration, phosphorus is considered as a vital nutrient which plays an important role in cell membranes, energy metab- 
olism through the metabolic pathway and it is also an important structural compound of bone [5,7]. Unlike ruminants, swine unable to produce phytase enzyme which can't digest the phosphorus in plant sources as is primarily stored in the form of phytates in plant seed $[6,8]$. On the other hand, ruminants such as sheep and cattle easily digested the plants' phosphorus, because microbes that are present in the rumen produces an enzyme i.e. phytase and it easily digests the plants' phytin phosphorus [8]. In a species like pigs, endogenous mucosal phytase appears incapable of hydrolysing sufficient amounts of phytate-bound $\mathrm{P}$ as a consequence there is an excretion of large amounts of non utilized phosphorus in the manure [9]. Other vital nutrients such as protein, $\mathrm{Ca}, \mathrm{Cu}$, and $\mathrm{Zn}$ also ease of access from phytates. Usually, a phosphorous reserve of plant origin contains 28.2 per cent phytic acid which accounts for about $50-80 \%$ of the total P (tP) in plant feedstuffs. In cereal grains that are not available for pigs [10-12]. As swine diets are primarily grain-based so it is necessary to identify the content of digestible $\mathrm{P}$ rather than total $\mathrm{P}$ for dietary phosphorus utilization efficiency [13].

Strategies for reduction of phosphorus excretion in swine

Generally, pigs are unable to digest phytates present in the feedstuff and excreted $70 \%$ of the phosphorus offered to a pig as dung $[6,14]$. To save the environment from pollution, we have to drop the levels of nitrogen and phosphorus from swine manure. But one of the main issues is that if we do not offer sufficient dietary phosphorus then the pigs may have phosphorus deficiency which leads to depressed growth and bone abnormalities [5]. So, regarding phosphorus feeding special care should be taken to recompense the deviation of phosphorus digestibility of feedstuffs. Furthermore, $\mathrm{P}$ consumption and excretion is a topic of immense concern, particularly for the intensive pig-producing countries. In the modern era of research, it becomes possible to diminish the $\mathrm{P}$ content of manure using biotechnological means [4,15]. Numerous new methodologies are developed and tested to improve the nutrient content or to alter the accessibility of nutrients of feedstuffs as well as improves its consumption by the animals. It was easy to incorporate certain enzymes, genetically modified feed substances and feed dispensation methodologies to improve the accessibility of nutrients so that they meet the requirements of specific animals and diminish the excretion of nutrients. Based on this in 2001, S.P. Golovan and coworkers developed 'Enviropig' through genetic engineering technique that could process phytates and able to digest plant phytate phosphorus.
Development of Enviropig a new perspective of phosphorus utilization

The Enviropig is the first transgenic Yorkshire pig is where Cassie (CA) line was generated, which obsessed a steady, low copy number of phytase transgene insertion that able to phytase secretion from the saliva and it becomes able to digest phytate on its own. In the recent era of research, it is possible to transfer foreign genes by somatic cell nuclear transfer (SCNT) and chiefly by nuclease-mediated genome editing tools, has offered to produce genetically modified (GM) pigs by competent ways for the dramatic upgrading of nutrient consumption competence and economic qualities $[16,17]$. This project was in progress at the University of Guelph in Ontario by biologist Cecil Forsberg, who genetically customized the pigs so that their salivary glands were able to secrete phytase which has been shown in the Cassie line of Enviropig. It was hemizygous for the phytase gene exhibited a genetic selection index known as Sire Line Index (SLI) which has $20 \%$ higher than that of the conventional pigs [2] in University of Guelph pigs. This allows the pigs, up to eighth-generation can utilize phosphate from a grain-based diet and excrete 40 per cent less unutilized dietary phosphorus [17].

\section{Utilization of phosphorus by enviropig}

Enviropigs, which use plant phosphorus more efficiently by producing the enzyme phytase in their saliva, the pigs can degrade normally indigestible phytate, which would otherwise release phosphorous into the pigs' manure [18]. Golovan., et al. [19] reported that stipulation of salivary phytase enables primarily to complete digestion of dietary phytate phosphorus, and reduces the faecal phosphorus excretion by the pigs by up to $75 \%$. Following are some of the environmental benefits of Enviropig;

- Enviropig can utilize dietary phosphorus which eliminates the additional dietary expensive supplemental phosphorus or phytase.

- $\quad$ Excrete 30 to $70 \%$ less phosphorus in manure depending upon the age and diet.

- It also reduces the cost of swine production.

- $\quad$ Plummeting the environmental phosphorus content which may be due to swine manure.

- Enviropig can utilize nutrients more efficiently and gain slaughter weight earlier than the conventional one. 
Safety aspects of enviropig

Even though the transgenic and non-transgenic pigs had a similar growth pace but the health of the Enviropig ${ }^{\mathrm{TM}}$ did not show any troubles [20]. Currently, the Enviropig is not commercially available and nor its pork enters the food chain. The important policy for disposal of transgenic animals requires that the carcasses should be incinerated. But the main drawback of incineration is cost, odour, and air pollution, so the projected resolution is to compost. The Food and Drug Administration (FDA) is the major organization to decide whether Enviropig poses no threat to the community and the surroundings. FDA furnished guidance and regulation of Genetically Engineered Animals for the first time in 2008 as before that FDA never dealt with transgenic animals. Regardless of the economic and environmental advantage, it has been reported that genetic exploitation methodologies are the opportunity that a novel protein present in the transgenic organism might have allergenic properties which might be the reason for transgenic pigs have not yet been commercially used (Ferro., et al. 2014). Forsberg., et al. [21] reported that before commercialization of the Einviropig safety and risk assessment measures to be examined in the following five-fold way:

- Safety of the inserted DNA - the potential of interspecies transfer and toxicity after ingestion

- $\quad$ The food safety issue of the newly produced protein (phytase) - toxicity, allergenicity, and any other unintended effects

- Equivalence of composition to the original food

- $\quad$ Retention of nutritional value and

- Human dietary exposure

- Excreta from the Enviropig and their potential impact on water quality etc.

\section{Conclusion}

The first swine transgenic Yorkshire pigs which enabled phytase secretion in the saliva and can able to digest phytate are named as Enviropig. These type of pigs excretes 30 to $70 \%$ less phosphorus in manure depending upon the age and diet. It is not only reduces the feed costs, the Enviropig could help farmers comply with "zero discharge" rules that allow no nitrogen or phosphorous runoff from animal operations. At present, no transgenic animal has been approved for consumption and Enviropig also passes safety tests with the U.S. Food and Drug Administration [22].
Bibliography

1. Talukdar., et al. "Prospects and potentiality of improving pig farming in North Eastern Hill Region of India”. International Journal of Livestock Research 9.1 (2019a): 1-14.

2. Roy., et al. "The Enviropig ${ }^{\mathrm{TM}}$ : Reducing the environmental impact of animal agriculture through high health-status pigs that efficiently utilize dietary plant phosphorus". Journal of Biotechnology 136 (2008): 217-231.

3. Prasad., et al. "Enhancing phosphorus utilization for better animal production and environment sustainability". Current Science 108 (2015): 1315-1319.

4. Columbus., et al. "Phosphorus utilization in starter pigs fed high-moisture corn-based liquid diets steeped with phytase". Journal of Animal Science 88.12 (2010): 3964-3976.

5. Talukdar., et al. "Minerals and its impact on fertility of livestock: A review”. Agricultural Reviews 37.4 (2016): 333-337.

6. Petersen B. "POLLUTION: Transgenic pigs to the rescue". elife 7 (2018): e37641.

7. Joern BC and Sutton AL. "Phosphorus management in pork production". In: Factsheet PIG-10-02-03 (2006): 1-6.

8. Haque., et al. "Phytase - their biochemistry, physiology and application in Poultry". International Journal of Livestock Research 2.2 (2012): 30-41.

9. Humer., et al. "Phytate in pig and poultry nutrition". Journal of Animal Physiology and Animal Nutrition (Berl) 99.4 (2015): 605-625.

10. Ravindran., et al. "Phytin: occurrence, bioavailability and implications in poultry nutrition". Poultry and Avian Biology Reviews 6 (1995): 125-143.

11. Angel., et al. "Phytic acid chemistry: Influence on phytin-phosphorus availability and phytase Efficacy". Journal of Applied Poultry Research 11 (2002): 471-480.

12. Angel., et al. "Effect of dietary phosphorus, phytase, and 25-hydroxycholecalciferol on broiler chicken bone mineralization, litter phosphorus, and processing yields". Poultry Science 85 (2006): 1200-1211.

13. Talukdar., et al. "Swine feeding and rearing practices in the Peren district of Nagaland, India". Journal of Entomology and Zoology Studies 7.2 (2019b): 561-565. 
14. Lin., et al. "Nutritional strategies for reducing nitrogen, phosphorus and trace mineral excretions of livestock and poultry". Journal of Integrative Agriculture 16.12 (2017): 2815-2833.

15. Poulsen HD. "Phosphorus Utilization and Excretion in Pig Production”. Journal of Environmental Quality 29 (2000): 24-27.

16. Wang., et al. "Gene engineering in swine for agriculture". Journal of Integrative Agriculture 16.12 (2017): 2792-2804.

17. Talukdar., et al. "Enviropig: A new perspective of environmentfriendly livestock production". The North-East Veterinarian 20.1 (2021): 19-21.

18. Forsberg., et al. "The Enviropig physiology, performance, and contribution to nutrient management advances in a regulated environment: The leading edge of change in the pork industry". Journal of Animal Science 81.14 (2003): 68-77.

19. Golovan., et al. "Pigs expressing salivary phytase produce low phosphorus manure”. Nature Biotechnology 19 (2001): 741745 .

20. Streiffer., et al. "Genetically Engineered Animals and the Ethics of Food Labeling. Labeling Genetically Modified Food: The Philosophical and Legal Debate". (2007).

21. Forsberg., et al. "Genetic opportunities to enhance sustainability of pork production in developing countries: A model for food animals". In: Applications of gene-based technololgies for improving animal production and health in developing countries. H.P.S. Makkar and G.J. Viljoen (eds.) Springer, Dordrecht, Netherlands (2005): 429-446.

22. Meidinger., et al. "Digestive utilization of phosphorus from plant-based diets in the Cassie line of transgenic Yorkshire pigs that secrete phytase in the saliva". Journal of Animal Science 91.3 (2013): 1307-1320.

\section{Volume 3 Issue 12 December 2021}

(C) All rights are reserved by Papori Talukdar., et al. 